STRUČNI ČLANAK

Dr Ivana Popović*

\title{
VELIKA ODLUKA ZA MALE LJUDE (Komentar člana 35. Zakona o zdravstvenoj zaštiti Republike Srbije)
}

Deca predstavljaju budućnost jednog društva, čine jednu od najranjivijih i najosetljivijih populacionih kategorija i zbog toga uživaju najviši stepen zaštite svake države.

Prepoznajući da deci pripada posebna briga i pomoć, Konvencija Ujedinjenih nacija o pravima deteta proklamovala je da će u svim aktivnostima države koje se tiču dece, najbolji interesi deteta biti od prvenstvenog značaja, a strane ugovornice se obavezuju da detetu obezbede takvu zaštitu i brigu. ${ }^{1}$

Zakonom o zdravstvenoj zaštiti ${ }^{2}$ uređena su pitanja društvene brige za zdravlje stanovništva, opšteg interesa u zdravstvenoj zaštiti, kao i prava i obaveze pacijenata, uključujući i prava i obaveze dece kao uživalaca prava na zdravstvenu zaštitu. Propisima zdravstvenog osiguranja, javnog zdravlja, kao i porodičnog i krivičnog prava regulišu se osetljivi odnosi deteta i drugih organa i subjekata koji učestvuju u radu na polju obezbeđivanja sveobuhvatne, pravične i svima jednako dostupne zdravstvene zaštite.

Oblast prava i dužnosti pacijenata, kao i bliže pravno određivanje odnosa između lekara i pacijenta regulisani su sa dvadeset članova Zakona o zdravstvenoj zaštiti. Članom 35. ovog zakona regulišu se - gledano sa pozicije lekara praktičara u vezi sa prihvatanjem medicinske procedure - prava onih pacijenata koji su maloletna lica ili lica lišena poslovne sposobnosti.

Član 35. glasi: (1) Ako je pacijent maloletan ili je lišen poslovne sposobnosti, medicinska mera nad njim može se preduzeti uz obaveštenje i pristanak njegovog zakonskog zastupnika (roditelj, usvojitelj ili staratelj). (2) Nadležni zdravstveni radnik koji smatra da zakonski zastupnik pacijenta ne postupa u najboljem interesu deteta ili lica lišenog poslovne sposobnosti dužan je da o tome odmah obavesti organ starateljstva. (3) Dete koje je navršilo 15. godinu života $i$ koje je sposobno za rasuđivanje može samo dati pristanak na predloženu

* Studentkinja specijalističkih studija Pravnog fakulteta Univerziteta Union u Beogradu, Dom zdravlja Sečanj

1 Konvencija o pravima deteta, „Službeni list SFRJ - Međunarodni ugovori“, br. $15 / 1990$.

2 Zakon o zdravstvenoj zaštiti Republike Srbije, „Službeni glasnik RS“, br. 107/05. 
medicinsku meru. (4) Poslovno nesposoban pacijent treba i sam da bude uključen u donošenje odluke o pristanku na predloženu medicinsku meru, u skladu sa njegovom zrelošću i sposobnošću za rasuđivanje.

U nekim aspektima, donošenje medicinskih odluka od strane dece i adolescenata odslikava šira i dobro poznata pitanja koja se ne tiču samo ovog zakonskog akta - pitanja širine autonomije koje bi dete trebalo da ima prilikom samostalnog donošenja odluke o sopstvenom lečenju i da li bi uopšte trebalo da ima dozvolu za takvu odluku, kao i koliki opseg bi uticaj roditelja trebalo da ima nad odlukama deteta. ${ }^{3}$

\section{PRAVO NA SAMOODLUČIVANJE I PRISTANAK}

\section{NA MEDICINSKU PROCEDURU}

„Kako sa etičkog, tako i sa pravnog stanovišta, sam pacijent ima pravo da odluči šta je u njegovom/njenom najboljem interesu. Sve odrasle osobe imaju sposobnost za odlučivanje ako mogu da razumeju sve relevantne informacije. "4

Pravo na prihvatanje medicinske procedure ${ }^{5}$ omogućuje ispoljavanje lične autonomije pojedinca u kontaktu sa zdravstvenom zaštitom. Prema pojedinim autorima, autonomija predstavlja slobodu delanja, dostojanstvo, slobodu volje i nezavisnost. ${ }^{6} \mathrm{U}$ domaćoj literaturi se mogu pronaći stanovišta da se samoodlučivanje o sopstvenom lečenju poistovećuje sa pojmom samoodređenja, odnosno da se pravom na samoodlučivanje „poštuje stav individualizma, koji apsolutizuje individualna prava sa idejom: volja bolesnika je vrhovni zakon (voluntas aegroti suprema lex) i da je čovek u svemu slobodan da odluči o svom zdravlju“"?

Kroz istoriju razvoja koncepta informisanog pristanka može se pratiti i napredak zajednice donosilaca javnih zdravstvenih politika u pogledu težnji da se osnovni principi ljudskih prava inkorporiraju u zakonske okvire koji direktno određuju odnos lekara i pacijenta. Počevši od takozvanog paternalističkog stava ${ }^{8}$, na kome se prvobitno zasnivao čitav odnos lekar - pacijent,

3 Jennifer L. Rosato, Foreword: Medical Decision Making for Children/Adolescents, Houston Journal of Health Law \& Policy, http://www.law.uh.edu/hjhlp/Issues/Vol_82/ Rosato.pdf, 22.12.2009.

4 Nicholas A. Boon, Niccki R. Colledge, Brian R. Walker, John A. A. Hunter, Davidson's Principles \& Practice of Medicine, New York 2006, str. 11.

5 Osim izraza „prihvatanje medicinske procedure“, u novijem javno-zdravstvenom rečniku koristi se izraz „,informisani pristanak“, kao direktni prevod engleskog pojma informed consent i nadalje će se u ovom radu ova dva termina paralelno koristiti.

6 Alasdair Maclean, Autonomy, Informed Consent and Medical Law, A Relational Challenge, Cambridge 2009, str. 10.

7 Jovan Marić, Medicinska etika, Beograd 1998, str. 315.

8 Prema savremenom paternalističkom modelu, doktori su staratelji pacijenata i sprovode u delo ono što je najbolje za njih. Oni otkrivaju šta je to najbolji interes pa- 
pa preko konzumentskog stava, ${ }^{9}$ danas se teoretski okvir, koji teži definisanju praktičnog odnosa između pružalaca zdravstvenih usluga i njihovih korisnika, premestio na „proces zajedničkog donošenja odluke, model koji želi da obuhvati i autonomiju pacijenata i odgovornost doktora za blagostanje pacijenata". 10

Osim pretpostavke dobrovoljnosti i sposobnosti da se određena medicinska mera prihvati i/ili odbije, pristanak na određenu medicinsku proceduru podrazumeva da se odluka pacijenta o predloženoj medicinskoj meri formira pre svega na osnovu informacija dobijenih od lekara (otud i pojam informisani pristanak). Prilikom donošenja odluke o prihvatanju medicinske procedure, očekivano je da pacijenti u čitav proces unose i svoje prethodno formirane stavove i vrednosti. Ipak, informacije dobijene od zdravstvenih radnika o vrsti predložene mere, dužini lečenja, troškovima lečenja, rizicima koje određena procedura nosi, alternativnim mogućnostima lečenja itd., jesu informacije od presudnog značaja za samostalno donošenje odluke o sopstvenom lečenju.

Svaki lekar je dužan da pacijentu, shodno njegovim godinama i stepenu razvoja ličnosti, pruži sve neophodne informacije koje bi mogle biti od značaja za donošenje odluke o prihvatanju medicinske procedure. Lekari koji to ne učine podležu pravnoj odgovornosti za takvo nečinjenje. ${ }^{11}$

\section{ZAKONSKI I ETIČKI OKVIR ZA INFORMISANI PRISTANAK MALOLETNIH LICA}

\section{MALOLETNA LICA I KONCEPT POSLOVNE SPOSOBNOSTI}

„Dobni interval od 10 do 26 godina, kao prelazak iz detinjstva u zrelost, $u$ kome se gubi privilegija deteta, a stiču prava i obaveze odrasle osobe, obeležen je dubokim promenama koje se odnose na biološki rast, seksualno, kognitivno, emotivno i psihosocijalno sazrevanje. U skladu sa tim, mlade osobe uspostavljaju kontrolu nad sopstvenim životom, donose odluke i snose posledice sopstvenih odluka i ponašanja."12

cijenta sa ograničenom participacijom njih samih (Momčilo Babić, Savremena bolnica, Medicinski fakultet Univerziteta u Beogradu, http://www.med.bg.ac.yu/dloads/ nastavni\%20bolnica/21\%20INFORMISANI\%20PRISTANAK.pdf, 22.12.2009).

9 Prema ovom modelu doktori unose u terapijsku situaciju činjenice, a pacijenti vrednosti. Ovaj model pretpostavlja jasno razlikovanje činjenica od vrednosti, a pacijentova autonomija dobija apsolutnu prevagu nad doktorovom odgovornošću za pacijentovu dobrobit (Momčilo Babić, op. cit.).

10 Ibid.

11 Vidi član 32. Zakona o zdravstvenoj zaštiti Republike Srbije.

12 Strategija za razvoj i zdravlje mladih u Republici Srbiji, Ekspertska grupa za razvoj i zdravlje mladih, Ministarstvo zdravlja Republike Srbije, 2006. 
Prema Svetskoj zdravstvenoj organizaciji, mladi, odnosno adolescenti, predstavljaju osobe starosne dobi između deset i 24 godine. Prema Zakonu o zdravstvenom osiguranju Srbije, zdravstvena zaštita se u punom obimu i bez plaćanja participacije omogućava „deci do 15 godina života, školskoj deci i studentima do kraja propisanog školovanja “. ${ }^{13}$ U skladu sa tim, možemo reći da se zakonski, period adolescencije u našoj državi pomera i do 26. godine.

Nasuprot činjenicama koje idu u prilog tome da se emotivna i kognitivna zrelost mlade osobe ne dosežu u potpunosti sve do sredine treće decenije života, pravna granica kojom se povlači linija između detinjstva i zrelog doba pomerena je mnogo niže.

Prema Porodičnom zakonu Republike Srbije ${ }^{14}$, punoletnim se postaje sa navršenom 18. godinom života, odnosno, maloletna lica su sva lica mlađa od 18 godina. Sa punoletstvom se stiče potpuna poslovna sposobnost. Shodno tome, sva maloletna lica su bez potpune poslovne odgovornosti. Lišavanjem lica poslovne odgovornosti, licu se, između ostalog, oduzima i mogućnost da samostalno donosi odluke koje se tiču načina njegovog/njenog lečenja.

Međutim, povezujući poslovnu sposobnost ne samo sa godinama starosti, već i sa drugim svojstvima ličnosti i prepoznajući duševnu i telesnu zrelost jedne osobe kao najvažniju karakteristiku u određivanju osobe kao kompetentne da vlada sopstvenim odlukama (uključujući i odluke vezane za prihvatanje medicinske procedure), naš pravni sistem, kao i zakonodavci većine „razvijenih zapadnih demokratija" u različitom obimu i u različitim situacijama priznaju poslovnu sposobnost i maloletnim licima. Uopšteno, u Srbiji potpuno poslovno sposobno može biti i maloletno lice koje je sklopilo brak, postalo roditelj i dostiglo „telesnu i duševnu zrelost potrebnu za samostalno staranje o sopstvenoj ličnosti, pravima i interesima“"15 Pojedinačno gledano, prema odredbama Porodičnog zakona, maloletno lice ukoliko dokaže da je sposobno za rasuđivanje (odnosno da je dostiglo određeni stepen emotivne i kognitivne zrelosti): sa 16 godina - može sklopiti brak; priznati očinstvo; dati saglasnost na priznanje očinstva (maloletna majka deteta, kao i maloletno dete); sa 15 godina - može imati uvid u matičnu knjigu i u drugu dokumentaciju koja se odnosi na njegovo poreklo; može odlučiti sa kojim će roditeljem živeti; može odlučiti o održavanju ličnih odnosa sa roditeljem sa kojim ne živi; odlučiti koju će srednju školu pohađati; preduzimati pravne poslove kojima upravlja i raspolaže svojom zaradom ili imovinom koju je steklo sopstvenim radom; može promeniti lično ime; sa 14 godina - može preduzimati pravne poslove kojima pribavlja isključivo prava, pravne poslove kojima ne stiče ni prava ni obaveze i pravne poslove malog značaja.

13 Pravilnik o sadržaju i obimu prava na zdravstvenu zaštitu iz obaveznog zdravstvenog osiguranja i o participaciji za 2009. godinu, član 23. stav 1 („Službeni glasnik RS“, br. 7/09).

14 Porodični zakon Republike Srbije, član 11. stav 1 („Službeni glasnik RS“, br. 18/05).

15 Vidi član 11. Porodičnog zakona Republike Srbije. 
Ne ulazeći dublje u pitanja postavljanja navedenih starosnih granica, vrlo je interesantno da su, prema Porodičnom zakonu, detetu koje je napunilo samo deset godina data prava koja na prvi pogled zahtevaju ipak nešto veće misaono ulaganje. Sa deset godina, dete u Srbiji može samostalno ili preko nekog drugog lica zatražiti: da mu se postavi privremeni zastupnik zbog postojanja suprotnih interesa između njega i njegovog zakonskog zastupnika; može zatražiti od organa starateljstva da mu postavi kolizijskog staratelja; može slobodno i neposredno izraziti svoje mišljenje u svakom sudskom i upravnom postupku u kome se odlučuje o njegovim pravima; ima pravo na davanje saglasnosti sa promenom ličnog imena; može se obratiti sudu ili organu uprave i zatražiti pomoć u ostvarivanju svog prava na slobodno izražavanje mišljenja.

Iako je naš zakonodavac predvideo širok opseg samostalnog pravnog delovanja maloletnih lica starih od deset do 17 godina, treba imati u vidu da nijedan zakonski akt maloletnicima/cama ne daje potpuno odrešene ruke u praktikovanju svojih prava, jer je svako pojedinačno pravo ograničeno uslovom da je za ostvarivanje datog prava neophodno da maloletno lice pokaže da je "sposobno za rasuđivanje“ ili da poseduje određeni „stepen telesne i duševne zrelosti“.

O praktičnim problemima određivanja stepena zrelosti i sposobnosti za rasuđivanje raspravljaće se u narednim odeljcima.

\section{OSVRT NA PRAVNE I ETIČKE PROBLEME INFORMISANOG PRISTANKA MALOLETNOG LICA}

„Etičke vrednosti i etički principi su uglavnom veoma bliski pravnim normama, ali ih većinom premašuju svojim obimom. U nekim slučajevima pravo zahteva neetičko ponašanje. Uopšteno gledano, ako lekar smatra da je pravo neetično, treba da teži da promeni pravo. "16

U Republici Srbiji, pravo da samostalno prihvati medicinsku proceduru ima maloletno lice staro 15 ili više godina koje je sposobno za rasuđivanje. $\mathrm{U}$ suprotnom, odluku o lečenju donosi zakonski zastupnik deteta.

Iako je u pogledu prava maloletnika na informisani pristanak dovoljno liberalan u poređenju sa nekim zakonima koji u državama u regionu regulišu ovu tematiku, ${ }^{17}$ naš zakonodavac se, nažalost, sem u tom članu Zakona o

16 American Medical Association, Code of Medical Ethics: Current Opinions with Annotations, 2008-2009, http://www.ama-assn.org/ama/pub/physician-resources/medicalethics/code-medical-ethics.shtml, 22.12.2009.

17 U Zakonu o zaštiti prava pacijenata Republike Hrvatske, zakonodavac se ni u jednom članu Zakona ne osvrće na prava maloletnih lica da prihvate predloženu medicinsku proceduru. Zakon se može preuzeti sa internet stranice Pravnog fakulteta, Sveučilišta u Zagrebu: http://www.pravo.hr/_download/repository/169_3_12_2004_Zakon_o_zastiti_prava_pacijenata.htm, 22.12.2009. 
zdravstvenoj zaštiti, ni u jednom drugom zakonskom aktu (pravilniku, odredbi) ili stručnom uputstvu/vodiču dobre kliničke prakse ne osvrće na praktične probleme primenjivanja ovog člana (samim tim i Zakona u širem smislu).

$\mathrm{U}$ većini država $\mathrm{SAD}$, sposobnost maloletnika da pristane na određenu medicinsku proceduru procenjuje se na osnovu statusa maloletnog lica i na osnovu tipa medicinske usluge koja se pruža maloletnom licu. ${ }^{18}$ Status maloletnika koji ima pravo na informisani pristanak određuju dva pojma, a to su emancipovan i zreo maloletnik. Kao emancipovano maloletno lice, država prepoznaje: onog maloletnika/cu koji/a se samostalno izdržava, i ne živi zajedno sa roditeljima; maloletno lice koje je stupilo u bračnu zajednicu; maloletna lica koja su postala roditelji i maloletna lica aktivna u vojnoj službi. ${ }^{19}$ Maloletnik za koga je procenjeno da je sposoban da razume kratkoročne i dugoročne posledice prihvatanja medicinske procedure, naziva se zrelim maloletnikom. ${ }^{20}$

Maloletno lice ima pravo da bez pristanka roditelja i bez njihovog obaveštavanja, samostalno zatraži i prihvati medicinsku proceduru u slučaju da od zdravstvene službe zahteva da „bude lečen od seksualno prenosivih infekcija, testiran na HIV, da zahteva da koristi kontracepciju, koristi usluge prenatalne nege, izvrši namerni prekid trudnoće, da se leči od bolesti iz oblasti mentalnog zdravlja, da mu se pruži hitna medicinska usluga i ako sa navršenih 12 godina života zahteva da se leči od upotrebe droga i alkohola." 21

Preokret u sudskoj praksi Velike Britanije, kada je reč o pravima dece mlađe od 18 godina da samostalno prihvate medicinsku proceduru, napravio je slučaj Gilik (Gillick case). ${ }^{22}$ Od tada se sposobnost da maloletno lice pruži informisani pristanak naziva i Gilikovom kompetencijom (Gillick competence). Najpoznatija sentenca ovog slučaja jeste stav sudije Lorda Frejžera „da niko ne može dati legalnu osnovu da se obavezno smatra da bilo ko mlađi od 16 godina nema sposobnost da pruži informisani pristanak za medicinsku proceduru, uključujući lečenje kontraceptivnim sredstvima. ${ }^{23}$

18 Minors' Rights in Medical Decision Making, JONA's Healthcare Law, Ethics, and Regulation, Lippincott's Nursing Center, http://www.nursingcenter.com/prodev/ce_article. asp?tid=739795, 22.12.2009.

19 Douglas Diekema, Ethics in Medicine, University of Washington School of Medicine, http://depts.washington.edu/bioethx/topics/parent.html, 22.12.2009.

20 Minors' Rights in Medical Decision Making, loc. cit.

21 Ibid.

22 Slučaj Gillick $v$ West Norfolk and Wisbech Area Health Authority je započeo sudsku praksu da deca mlađa od 16 godina mogu pravno osnovano dati pristanak na medicinsku proceduru, nezavisno od želja njihovih roditelja, ako dokažu da poseduju dovoljan stepen razumevanja i inteligencije (Shield J. P. H., Baum J. D., Children's consent to treatment, BMJ, izdanje 308, str. 1182-83).

23 Tony Hope, Medical Ethics: A Very Short Introduction, Oxford 2004, str. 125. 
Prema najnovijem vodiču za informisani pristanak za decu i mlade ljude, izdatom od strane Ministarstva zdravlja Velike Britanije (Department of Health), dete mlađe od 16 godina ima pravo na informisani pristanak, ali tek pošto dokaže da razume šta sve taj postupak podrazumeva. ${ }^{24}$

Dokaz da ni u ovim zemljama, kao ni u našoj, prava maloletnika na informisani pristanak nisu apsolutna, pruža i slučaj Re W., devojke koja je sa 16 godina zatražila od suda da joj se prizna pravo da odbije da bude veštački hranjena preko nazogastričnog tubusa. Sudija Lord Donaldson je te 1992. godine presudio da niko mlađi od 18 godina nema apsolutno pravo da samostalno donosi odluke vezane za medicinski tretman, posebno ako je ta odluka odbijanje medicinske procedure. ${ }^{25}$

\section{PRAKTIČNI PROBLEMI ODREĐIVANJA STEPENA ZRELOSTI DETETA}

Praktični problemi proizlaze iz činjenice da je lekar u stvari „prvi evaluator pacijentove sposobnosti da pruži pristanak na medicinsku proceduru“ ${ }^{26} \mathrm{U}$ najvećem broju slučajeva, on je i jedini evaluator. Teoretski, lekari bi mogli da se u slučaju sumnje u kompetentnost maloletnog lica obrate psiholozima i/ili psihijatrima za procenu njegove/njene sposobnosti za informativni pristanak, ali se u praksi to ne dešava tako često.

U još ređim prilikama (nešto češće u zemljama sa razvijenom sudskom praksom u ovoj oblasti medicinskog prava), kada je reč o ozbiljnim i komplikovanim slučajevima, može se i od nadležnog suda zatražiti da odluči o kompetentnosti maloletnika.

Tokom svog razvoja deca dostižu određeni stepen sposobnosti izražavanja i mišljenja. Detetovo poimanje bolesti se sa razvojem ličnosti takođe menja u toku odrastanja. Predškolska deca uglavnom bolest povezuju sa magičnim predstavama ili misle da bolest slučajno nastaje. U osnovnoj školi se razvija pojam zaraze (kontagioznosti) i deca su već tada u stanju da razumeju da se bolest dobija prenosom sa nekih površina ili od drugih ljudi. Starija deca već shvataju da bolest nastaje unošenjem „bacila“ u telo (putem jela ili udisanjem). Tek u adolescentnom periodu, mladi ljudi shvataju psihološka i kompleksnija objašnjenja bolesti. ${ }^{27}$

24 Consent - what you have a right to expect, A guide for children and young people, Department of Health, UK, http://www.dh.gov.uk/prod_consum_dh/groups/dh_digitalassets/@dh/@en/documents/digitalasset/dh_4116903.pdf, 22.12.2009.

25 Shield J. P. H., Baum J. D., op. cit.

26 Dan W. Brock, Patient Competence and Surrogate Decision Making, u: The Blackwell Guide to Medical Ethics, Malden 2007, str. 131.

27 Graham Douglas, Fiona Nicol, Colin Robertson, Macleod's Clinical Examination, New York 2005, str. 363. 
Nažalost, lekari kliničari, u svom svakodnevnom radu, nemaju dovoljno alata da mogu pouzdano i relativno brzo da procene stepen zrelosti deteta. Ponekad se u ispitivanju kompetentnosti deteta za donošenje odluke koriste razni minimental testovi, ${ }^{28}$ ali oni ne mogu biti primenjeni u graničnim slučajevima ispitivanja kompetentnosti osoba da prihvati određenu medicinsku proceduru. $^{29}$

\section{ZAKLJUČAK}

„Moderna medicinska nauka stvara nove moralne izbore i izazove, testirajući tradicionalne poglede koje i mi sami imamo."30

Od donošenja presude u slučaju Gilik, prava maloletnika na donošenje odluka koje se tiču reproduktivnog zdravlja prva su našla primenu u zakonodavstvima SAD i Velike Britanije. „Podjednako, to je i oblast u kojoj deca poseduju najveću autonomiju prilikom odlučivanja o medicinskom postupku. “31

Prihvatajući da je napredak u oblasti prepoznavanja pravnog subjektivizma maloletnog deteta neminovnost, poštujući napredak u oblastima socijalne, zdravstvene i pravne zaštite maloletnika, kao i preporuke Saveta Evro$\mathrm{pe}^{32}$ „da svi građani imaju pravo učestvovanja u procesima donošenja odluka koje se tiču zdravstvene zaštite", svi relevantni zainteresovani akteri u našoj zemlji trebalo bi da rade na proširenju zakonskog okvira koji reguliše oblast medicinskog prava, na promociji vrednosti normiranih prava pacijenata, na omogućavanju mladima da budu informisani o svojim pravima iz oblasti informisanog pristanka na njima dostupan, prihvatljiv i razumljiv način, na omogućavanju da budu aktivno uključeni u donošenje procedura koje će regulisati pitanja njihovih prava u oblasti zdravstvene zaštite, kao i da sutra budu ocenjivači poštovanja i primene tih procedura.

Ništa manje nije važno da se kreiranjem stručnih uputstava i alata, kao i pružanjem jasnih smernica u odlučivanju, pomogne i lekarima koji brinu o zdravlju dece, da - poštujući prava deteta iz oblasti medicinskog prava - direktno rade i na njihovom unapređenju.

28 Minimental test (engl. minimental) jedan je od najkorišćenijih testova za ispitivanje kognitivne funkcije koji se koristi u svakodnevnoj lekarskoj praksi. Služi kao test-orijentir prilikom ispitivanja kognitivnih poremećaja i njegovo trajanje obično ne prelazi deset minuta. Sastoji se od trideset kratkih pitanja.

29 Ibid.

30 Tony Hope, op. cit., str. 1.

31 Jennifer L. Rosato, loc. cit.

32 Recommendation No. R (2000) 5 of the Committee of Ministers to member states on the development of structures for citizen and patient participation in the decisionmaking process affecting health care, Council of Europe. 